\title{
Informes de Responsabilidad Social Corporativa (RSC): Fuentes de Información y Documentación
}

\author{
María Pilar Dopazo \\ Departamento de Derecho Administrativo. Universidad Complutense de Madrid \\ pilardo@icam.es
}

Recibido: Diciembre 2011

Aceptado: Junio 2012

Resumen: El compromiso hacia la RSC incluye no solo buen gobierno global, disciplina, sentido del deber, transparencia y rendición de cuentas (control público), sino también compromiso ético, participación y diálogo con los grupos de interés. Este artículo pretende contribuir a la creación de un marco estructurado de Reporting Corporativo -información y documentación en RSC- para analizar la Responsabilidad Social (RS) de la empresa. Con este objetivo, se resumen las principales actuaciones e instrumentos de información que integran los enfoques de la Responsabilidad Social Corporativa (RSC / RSE) y los principios de Desarrollo Sostenible en los sistemas de gestión de las organizaciones del sector privado/sector público.

Palabras clave: Responsabilidad Social Corporativa (RSC) - Responsabilidad Social Empresarial (RSE); Responsabilidad Social (RS); Informes de RSC - Memoria de Sostenibilidad; Transparencia informativa; Buen Gobierno Global; Reputación Corporativa.

\section{The Reporting of Corporate Social Responsibility (CRS): Information Sources and Documentation}

\begin{abstract}
The compromising towards the CSR includes not only the good global government, discipline, sense of duty, transparency and accountability, but also ethical compromising, participation and dialogue with stakeholders. This article aims to contribute to the establishment of a more structurally of Reporting Corporate -information and documentation of CSRoriented framework for analyzing the Social Responsibility (SR) of the enterprise. To this end, the article resumes the main actions and instruments of reporting integrating the Corporate Social Responsibility (CSR) and the principles of the Sustainability Developed by the systems management of organizations private sector/public sector.
\end{abstract}

Keywords: Corporate Social Responsibility (CSR); Social Responsibility (SR), Reporting of CSR - Sustainability Report. Transparency - Access to information; Good Global Government; Corporate Reputation.

\section{PLANTEAMIENTO PREVIO}

En el contexto social y económico actual, puede afirmarse que la noción de Responsabilidad Social Corporativa o Empresarial (RSC o RSE) recobra un 
especial interés y, con ello, su significado y triple dimensión adquieren su máximo valor funcional. De esta forma el concepto de Responsabilidad Social (RS) viene siendo interpretado como un compromiso voluntario de contribución social, económica y ambiental ${ }^{1}$ que ofrece una organización o entidad (cualquiera que sea su tipología o naturaleza jurídica); compromiso asumido y declarado públicamente, que deberá ser realizado de forma efectiva, por lo que implicará la previa configuración de un programa de acción propio y la realización de prácticas concretas congruentes con los principios internacionales de RSC/RSE ${ }^{2}$.

Por tanto, la noción actual de RSE supone la asunción voluntaria por parte de una organización de concretas "obligaciones jurídicas y sociales", cuyo cumplimiento podrá ser objeto de autoevaluación y auditoría, asimismo de evaluación y verificación por terceros independientes. En todo caso, hoy la RSC/RSE se configura como un auténtico objetivo vinculado al logro del crecimiento sostenible, siendo -a su vez- un instrumento estratégico que debe ser integrado en el sistema de gestión implementado por una organización. En consecuencia, hay que reconocer la importancia nuclear de este concepto, más allá de su consideración teórica o de su aplicación como simple herramienta de marketing, la RS se erige como un poderoso "factor del emprendimiento", que una vez adoptado e integrado en el seno de cada entidad funciona como un instrumento operativo que aportará valor empresarial. Esto es, la RS implementada de forma eficaz, permitirá distinguir a las entidades "responsables y sostenibles", en el

1 El concepto actual de "Corporate Social Responsibility" (CSR) ha sido definido como "la asunción de la obligación de llevar el comportamiento corporativo a un nivel superior en el que sea congruente con las normas, valores y expectativas sociales existentes y no sólo con los criterios económicos y legales" (Fernández, R. Administración de la responsabilidad social corporativa. Madrid: Thomson, Colección Negocios, 2005). En el mismo sentido, la investigadora del ILPES-CEPAL, $\mathrm{M}^{\mathrm{a}}$ Emilia CORREA, conforme al pronunciamiento del World Business Council for Sustainable Development (WBCSD), defiende que la Responsabilidad Social "es el compromiso que asume una empresa para contribuir al desarrollo económico sostenible por medio de la colaboración con sus empleados, sus familias, la comunidad local y la sociedad en pleno, con el objeto de mejorar la calidad de vida" (CORREA, M.E. "Responsabilidad social corporativa en América Latina: una visión empresarial". Serie Medio Ambiente y Desarrollo, Santiago de Chile, 2004, $n^{\circ}$ 85, pp.15-18). De igual modo, MORENO, J., Responsabilidad social corporativa y competitividad: Una visión desde la empresa, en AA.VV., VARGAS, L. (coord.), Mitos y realidades de la responsabilidad social corporativa en España. Un enfoque multidisciplinar. Navarra: Thomson-Civitas, 2006, 187-223 pp.

${ }^{2}$ La ONU, en 1999, impulsó la iniciativa Global Compact-Pacto Mundial-reconociendo los calificados como los "Diez Principios básicos de la RSC", basados en derechos humanos, cuestiones sociales-laborales, medioambientales y de lucha contra la corrupción. Disponible en http://www.pactomunidal.org/ (Fecha de consulta: 5-1-2012). 
mercado global, frente a su competidores ${ }^{3}$. Asimismo, como hemos avanzado, la RS per se supone un objetivo de progreso y desarrollo empresarial, siendo reconocida como un presupuesto clave a la hora de proyectar todo proceso de internacionalización empresarial. En efecto, al respecto cabe afirmar que la RS, con toda probabilidad hoy más que nunca ${ }^{4}$-, se configura como un requerimiento cualitativo exigible a todo operador que actúe en los mercados internos e internacionales; y así es reivindicado por todos los grupos de interés stakeholders- (inversores, gobiernos y autoridades reguladoras, sociedades, entre otros). En atención a dicho requerimiento, las entidades que pretendan asegurarse un determinado posicionamiento mercantil y ser competitivas, no podrán eludir u obviar la RS (sus compromisos en este ámbito), pues en su defecto podrían sufrir perjuicios y riesgos reputacionales de difícil reparación. En este sentido, y a tenor de la propia complejidad del presente escenario dibujado por la globalización económica, el emprendimiento social empresarial (actuaciones, prácticas o/y conductas empresariales en RS) se configura como una manifestación -concreción material y efectiva- del concepto de RSC/RSE, observando en todo caso sus principios y actuando conforme al triple enfoque material (económico, social y ambiental) que comprende e ilustra dicha noción ${ }^{5}$.

3 Sobre los presupuestos necesarios para la calificación de "organización o empresa responsable", vid., OLCESE, A., RODRÍGUEZ, M.A. y ALFARO, J. Manual de la empresa responsable y sostenible. Madrid: McGraw-Hill, 2008, 321 y 322 pp. Y, TORTOSA, E. "Responsabilidad social de la empresa: un nuevo modelo de empresa". Papeles de Economía Española, $\mathrm{n}^{\circ} .108 .2006,106$ y ss. pp.

${ }^{4}$ En especial ante la complejidad de los efectos producidos por la crisis global, con fuerte repercusión social, al respecto POZO FERNÁNDEZ, R. del.: "El valor de la responsabilidad social corporativa en un entorno de crisis". Estrategia Financiera: Revista para la Dirección Financiera y Administrativa, $\mathrm{n}^{\circ} .257$ enero 2009, 30-33 pp.

$5 \mathrm{Al}$ respecto, en el marco internacional, destacan los siguientes pronunciamientos: la iniciativa de Naciones Unidas (ONU, 1999) del Global Compact o Pacto Mundial, reconociendo los calificados como Diez Principios básicos de la RSC, que se centran en la protección de los derechos humanos, derechos sociales y laborales, protección del medioambiente y otras cuestiones, como la lucha contra la corrupción (disponible en http://www.pactomunidal.org/). Dicha iniciativa mundial, fue promovida con la finalidad de alcanzar un compromiso voluntario en materia de RSC por parte de organizaciones/entidades o empresas. Asimismo, la OCDE emitió la Declaración de la OCDE sobre Inversión Internacional y Empresas Multinacionales, disponible en http://www.oecd.org/dataoecd/21/20/ 16975360.pdf (Consulta realizada: 5-1-2012), ofreciendo un conjunto de recomendaciones a las empresas multinacionales que voluntariamente adopten códigos de conducta empresarial responsable sobre distintas cuestiones, entre otras, cabe destacar las referentes a la elaboración y publicación de informes corporativos y, de forma específica, al debido tratamiento que debe prestarse a los temas ambientales y sociales, empleo y relaciones laborales, lucha contra la corrupción, protección de los intereses de los consumidores, investigación, ciencia y tecnología, competencia y fiscalidad. 
Conforme a este planteamiento y motivación, todo tipo de organización debe implementar adecuados sistemas de gobernanza y de gestión integrada de la RS; y, de igual modo, ha de asumir y declarar un compromiso concreto de cumplimiento y mejora continua en este ámbito. Dicha declaración de compromiso será documentada y hecha pública por cada entidad, pudiendo ser objeto comunicación interna/externa. A su vez, el compromiso declarado por una empresa en esta materia, ha de ser "efectivo", lo que implicará demostrar en la práctica -y de forma típica y habitual- la realización de conductas/prácticas sociales y medioambientales "responsables"; y, por ende, acreditar una actuación empresarial congruente con las propias políticas empresariales previamente declaradas y, asimismo, ofrecer unos resultados verificables al respecto. De este modo, los objetivos de RS declarados e implementados por cada compañía configuran su

Por su parte, en el ámbito de la Unión Europea, hay que destacar la publicación del Libro Verde de la Comisión Europea: fomentar un marco europeo para la responsabilidad social de las empresas, aprobado por la Comisión Europea, el 18 de julio de 2001, COM (2001) 366, julio de 2001 (disponible en http://eur-lex.europa.eu/LexUriServ/site/es/com/2001/ com2001_0366es01.pdf, consulta realizada: 10-1-2012). Y, posteriormente, en julio de 2002, se emitió por la Comisión Europea la "Comunicación de la Comisión Europea relativa a RSE: una contribución empresarial al desarrollo sostenible", en Bruselas el 2 de Julio de 2002, COM (2002) 347 final (disponible en http://eur-lex.europa.eu/LexUriServ/LexUriServ.do? uri=COM:20-02:0347:FIN:ES:PDF. Consulta realizada: 10-1-2012) Asimismo, en julio de 2002, a iniciativa de la Comisión Europea, se constituye el Foro Europeo Multistakeholders, con el propósito de fomentar la participación activa de los principales representantes de la sociedad civil en los debates y trabajos propiciados en materia de RSC. Las conclusiones resultado de dicho Foro de debate fueron recogidas en un Informe único de junio de 2004, y la Comisión Europea emitió la "Comunicación para poner en práctica la asociación para el crecimiento y el empleo: hacer de Europa un polo de excelencia de la Responsabilidad Social de las Empresas", Bruselas, 22 de marzo de 2006, COM (2006) 136 final, disponible en http://eur-lex.europa.eu/LexUriServ/LexUriSErv.do?uri=COM20-06:0136:FIN:ES:PDF (Consulta realizada: 12-1-2012).

Cabe añadir a las iniciativas precitadas, los trabajos de la Comisión Europea en materia de transparencia y derechos humanos, de igual modo los informes generados por la ONU entre los años 2007 y 2011; asimismo, la "Declaración del Milenio", firmada en el año 2000 por 189 países, fijando una serie de compromisos y objetivos en torno a disminuir los índices de pobreza para el año 2015 (http://www.un.org/spanish/milenio/ares552.pdf).

En la actualidad, en el ámbito de la Unión Europea, es necesario hacer referencia a la Comunicación de la Comisión Europea: "Estrategia renovada de la Unión Europea para 2011-2014 sobre Responsabilidad social de las empresas (RSE)", por su valor como documento marco para la reflexión europea, si bien sin carácter normativo vinculante $(c f r$., Comunicación de la Comisión Europea al Parlamento Europeo, al Consejo al Comité Económico y Social Europeo y al Comité de las Regiones: Estrategia renovada de la Unión Europea para 2011-2014 sobre responsabilidad social de las empresas (RSE), de 25 de octubre de 2011, COM (2011) 681 final. Disponible en www.eur-lex.europa.eu (Consulta realizada: $26 / 3 / 2012$ ). 
cultura corporativa ${ }^{6} \mathrm{y}$, en todo caso, por sí mismos constituyen una destacada fuente de conocimiento y de información corporativa $-\mathrm{o}$, en su caso, societariaque deberá ser accesible, facilitando su conocimiento e interpretación por parte de los distintos sujetos interesados, sociales y económicos ${ }^{7}$; esto es, para todos los grupos de interés (stakeholders) previamente identificados (inversores, autoridades reguladoras, sociedad, otros). Funcionando como dicha fuente de información, la "RS declarada y ejercitada" de forma periódica por cada entidad -v.gr., a través de la elaboración y emisión de Informes de RSC o Memorias de Sostenibilidad ${ }^{8}$, por lo general de forma anual o bianual- podrá ser de gran utilidad para proceder a identificar, valorar y calificar a cada una de las empresas $u$ operadores en el mercado. Al mismo tiempo, los citados informes permitirán evaluar y diagnosticar las políticas y prácticas seguidas por cada compañía, así como estimar los (propios) modelos empresariales (v.gr., estructuras organizativas, sistemas de gobierno, sistemas de gestión, programa de actividades, acciones empresariales

${ }^{6}$ El vocablo de "cultura corporativa" o "cultura empresarial" ha sido definido como "el conjunto de valores, normas y comportamientos que dispone una empresa, sobre la que construye tanto su estructura directiva como organizativa, así como las relaciones entre los miembros de la propia organización y las relaciones con su entorno". (GARCÍA ECHEVARRÍA, S. y DEL VAL NÚÑEZ, M.T. Cultura corporativa y competitividad de la empresa española. Madrid: Díaz de Santos, 1993). Por tanto, en virtud de la definición referida $\mathrm{y}$, a su vez, considerando cierto que en la práctica el factor de la competitividad de una compañía descansa en las propias diferencias marcadas por/entre las empresas, podemos afirmar que el mantener y desarrollar dichas diferencias, sobre todo aquellas que aporten un valor añadido como la RS, permitirá a una entidad u operador destacarse en el mercado, generando una percepción positiva en los grupos de interés (buena reputación). De este modo, podemos inferir que la RSE ha de ser un factor clave y orientador para la dirección estratégica de toda entidad o empresa (sector privado y/o público).

${ }^{7}$ NIETO, M. "Difusión de la responsabilidad social corporativa en la empresa española". Economistas, $\mathrm{n}^{\circ} 106,2005,32$ y ss. pp.

${ }^{8}$ Hay que señalar que en nuestro país el primer informe de RSC fue publicado en el año 2001, siguiendo en líneas generales como referencia los modelos operados para la elaboración de informes ambientales o de gestión medioambiental. Al respecto, se ha manifestado que "España es el cuarto país en número de informes de RSC. Esta cantidad ha aumentado en un $136 \%$ desde 2005. El porcentaje de información presentada en materia de responsabilidad corporativa en España se sitúa por encima de la medida en todos los sectores del estudio $(\ldots / \ldots)$. La integración de la información sobre responsabilidad corporativa en los informes anuales convencionales está aún lejos de ser algo habitual en España. Un tercio de las compañías estudiadas no informa sobre responsabilidad corporativa en absoluto, mientras que aproximadamente una tercera parte publica un informe de responsabilidad corporativa, por separado de sus informes anuales. España ocupa un puesto destacado en cuanto al número de compañías que someten sus informes a verificación externa, situándose en la cabeza del grupo de entre los países estudiados". BLASCO VÁZQUEZ, J.L. y ELORTZ ARTEGA, I. "Informes de responsabilidad corporativa: la historia de un éxito". Estrategia Financiera, n ${ }^{\circ} .257$. enero, 2009, 26-29 pp. (en concreto, cita referida en p.28). 
operadas, entre otros aspectos de interés), observando la evolución seguida en cada caso y los progresos alcanzados en este ámbito.

En consecuencia, cabe afirmar que hoy y a futuro la Responsabilidad Social Corporativa (RSC o RSE) - o, siendo más específicos, el sistema propio de gestión de la RSC implementado en su caso por cada entidad- se considera como un factor estratégico esencial para el desarrollo empresarial (de cualquier tipo de organización), que permitirá reforzar la credibilidad con respecto al emprendimiento operado, la buena gobernanza y el principio de transparencia informativa. En este sentido, hay que señalar que el tratamiento de la información aportada en materia de RS es una cuestión que debe ser abordada por una compañía con la máxima diligencia, por ser relevante a los efectos de mostrar el grado de integración del factor de la RSC practicado por una organización/empresa en cada caso concreto. De este modo, la información corporativa en RS constituye un valioso indicador aplicable, por ejemplo, para proceder al examen y valoración del grado de cumplimiento regulatorio global observado por una entidad (compliance) y, asimismo -en su caso- auto-regulatorio. Dicha evaluación, podrá ser considerada como válida en términos relativos, permitiendo su comparación entre los distintos sujetos/operadores (del mismo o distinto sector de actividad económica), en atención a su nivel de compromiso y conducta "responsable". Con todo, conviene puntualizar que dicha consideración es cada vez más apreciada por los mercados, siendo fuente de información para proceder a la calificación de los operadores ${ }^{9}$. La valoración de la RSC será necesaria para obtener una determinada (pretendida) calificación favorable como "empresa responsable", frente a otros posibles sujetos u actores que no acreditaran disponer de dicho atributo cualitativo. Al respecto, en el presente hay que señalar que las principales organizaciones líderes de los distintos sectores ${ }^{10}$-sector

${ }^{9}$ A modo de referencia, entre otras las calificaciones ofrecidas con base al criterio de la inversión socialmente responsable realizadas por las distintas compañías (vid., Índice de Sostenibilidad Dow Jones, FTSE4Good y el listado ofrecido por el "The Global 100 Most Sustainable Corporations"); asimismo, las calificaciones operadas atendiendo a la pertenencia a asociaciones/club o/y redes de RSE (UN Global Compact y World Business Council for Sustainable Development), entre otras.

${ }^{10}$ La consultora KPMG elabora un estudio internacional -con periodicidad bianual- en el que se analiza la evolución seguida en los informes de RSC publicados por las empresas consideradas más relevantes del mundo, en dicho estudio se observan las principales tendencias en cuanto al contenido ofrecido por estos informes, sirviendo así para evaluar las mejoras acometidas al respecto, $c f r$., El informe "KPMG International Survey of Corporate Responsibility Reporting 2011" Disponible en http://www.kpmg.com/es/es/ actualidadynovedades/articulosypublicaciones/paginas/kpmg-international-survey-of-corporateresponsibility-reporting-2011.aspx (Última consulta realizada:3-5-2012). Con respecto a los resultados obtenidos en virtud del citado Informe 2011, cabe señalar que sí se aprecia un incremento de la información no financiera en el contenido de este tipo de informes ofrecidos por las compañías. Asimismo, por países, España figura como el séptimo país del mundo en la 
financiero y no financiero- ya vienen apreciando el valor añadido que aporta la $\mathrm{RSC} / \mathrm{RSE}$ para el desarrollo y posicionamiento empresarial ${ }^{11}$. Y, de este modo, es posible reconocer la relación existente (causa/efecto) entre $R S /$ emprendimiento social y reputación corporativa, conceptos que quedan así vinculados y -ademásse retroalimentan entre sí. En consecuencia, las empresas "socialmente responsables" son conocedoras de la importancia real que conlleva -en la prácticala aplicación de herramientas específicas de autoevaluación e información pública de la $\mathrm{RS}^{12}$. En este sentido, resulta fundamental hacer hincapié en los medios habilitados por cada entidad para la información y de comunicación interna/externa de las acciones desarrolladas en esta materia (v.gr., Reporting de RSC y/o Memorias de Sostenibilidad). Si bien, es digno reconocer que en este ámbito queda mucho por hacer, cierto es que son importantes los logros alcanzados en este sentido, como demuestra el incremento progresivo en la emisión y publicación de Informes de RSC/RSC-Memorias de Sostenibilidad por parte de compañías y organizaciones de todo tipo, naturaleza jurídica y sector operativo.

\section{RESPONSABILIDAD SOCIAL, DERECHO DE ACCESO A LA INFORMACIÓN Y TRANSPARENCIA INFORMATIVA}

El derecho a la información pública es reconocido por el artículo 105 b. de la Constitución española de 1978, siendo desarrollado, con carácter general, en los artículos 35 y 37 de la Ley 30/1992, de 26 de noviembre, de Régimen jurídico de

aplicación de la RSC, conforme KPMG informa en nota de prensa publicada en http://www.kpmg.com/es/es/actualidadynovedades/articulosypublicaciones/notasdeprensa/pagi nas/np-aplicacion-rsc.aspx (Consultada: 3:-5-2012).

${ }_{11}$ Conforme a los resultados aportados por el estudio elaborado por OLCENSE SANTOJA, A. (Director), Creación de Valor y Responsabilidad Social de la Empresa (RSE) en las Empresas del IBEX 35. Madrid: Real Academia de Ciencias Económicas y Financieras, Febrero 2011. 69-82 pp. En el mismo sentido, CHARLO, M. y MOYA, I. "El comportamiento financiero de las empresas socialmente responsables". Investigaciones Europeas de Dirección y Economía de la Empresa. Vol. 16-2, 2010, 15-26 pp.

${ }^{12}$ Cfr., Comisión Europea, Internal Market and Services DG (Free Movement of Capital, Company Law and Corporate Governance): Summary Report of The Responses Received to The Public Consultation on Disclosure of Non-Financial Information by Companies Directorate General for The Internal Market and Service. April 2011. Executive Summary (EU), disponible en http://ec.europa.eu/internal_market/consultations/docs/2010/non-financial_reporting/ summary_report_en.pdf(Û́tima consulta realizada: 23-4-2012). Entre otros resultados ofrecidos por la encuesta realizada, una gran mayoría de los encuestados considera que es necesario aportar una mejor y más completa información referente a los aspectos no financieros, estimando la conveniencia de ofrecer informes integrados para poder valorar la conducta empresarial. 
las Administraciones públicas y del Procedimiento administrativo común ${ }^{13} \mathrm{y}$, con carácter especial, en leyes como la Ley 27/2006, de 18 de julio, reguladora de los derechos de acceso a la información, de participación pública y de acceso a la justicia en materia de medio ambiente (incorporando las Directivas 2003/4/CE y 2003/35/CE) $)^{14}$, y la Ley 37/2007, de 16 de noviembre, sobre reutilización de la información del sector público ${ }^{15}$, entre otros textos normativos. Por otra parte, en esta materia, hay que citar el actual Anteproyecto de Ley de Transparencia, acceso a la información pública y buen gobierno ${ }^{16}$, presentado por el Gobierno español con fecha de 23/3/2012-, que contiene disposiciones relativas al ejercicio de este derecho con respecto a la publicidad activa y su aplicación a todas las Administraciones públicas, instituciones y entidades/empresas públicas y a las personas que presten servicios públicos o ejerzan potestades administrativas.

De igual modo, en el Ordenamiento jurídico español el principio de la transparencia informativa es consagrado en distintos cuerpos legales en materia mercantil ${ }^{17}$, constituyéndose como un requerimiento técnico y jurídico exigible,

${ }^{13}$ Cfr., BOE núm. 285, 27 de noviembre de 1992, rect. BOE núm. 311, de 28 de diciembre de 1992 y BOE núm. 23 de 27 de enero de 1993.

${ }^{14}$ Cfr., BOE núm. 171, de 19 de julio de 2006.

${ }^{15}$ Cfr., BOE núm. 276, de 17 noviembre 2007.

${ }^{16}$ Cfr., Ministerio de la Presidencia, Gobierno de España, "Informe sobre el Anteproyecto de Ley de Transparencia, acceso a la información pública y buen gobierno" (23-3-2012), disponible en http://www.lamoncloa.gob.es/consejodeministros/Resumenes/2012/230312-consejo.htm,

http://www.mpr.es/es/noticias/2743/el-gobierno-presenta-la-ley-de-transparencia.html

Texto del Anteproyecto de Ley de Transparencia, acceso a la información pública y buen gobierno. Disponible en http://estaticos.elmundo.es/documentos/2012/03/26/ley_transparencia....

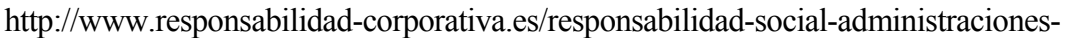
publicas/responsabilidad-social...."Informe sobre el Anteproyecto de Ley de transparencia, acceso a la in formación pública y buen gobierno". Diario del Derecho (26/03/2012 - Actualidad), disponible en http://www.iustel.es (RI §1057818). (Consultas realizadas: 26-3-2012).

${ }^{17}$ Al respecto, cabe referir la denominada Ley de Transparencia, Ley 26/2003, de 17 de julio, por la que se modifican la Ley 24/1988, de 28 de julio, del Mercado de Valores, y el texto refundido de la Ley de Sociedades Anónimas, aprobado por el Real Decreto Legislativo 1564/1989, de 22 de diciembre, con el fin de reforzar la transparencia de las sociedades anónimas cotizadas (BOE núm. 171 de 18 de julio de 2003). Por otra parte, recientemente, la Ley 2/2011, de 4 de marzo de Economía sostenible (LES), BOE núm. 55, de 5 de marzo de 2011, en su Disposición final quinta (Tres), modifica la Ley 24/1988, de 28 de julio, del Mercado de Valores, incorporando en el Título IV un nuevo Capítulo VI: "Del Informe anual de gobierno corporativo", dentro del mismo, el art. 61 bis determina que "1. Las sociedades anónimas cotizadas deberán hacer público con carácter anual un informe de gobierno corporativo.", que deberá ser comunicado a la Comisión Nacional del Mercado de Valores, que remitirá copia del informe comunicado a las respectivas autoridades de supervisión cuando se trate de sociedades cotizadas. Dicho informe será objeto de publicación como hecho relevante y su contenido y estructura vendrá determinado por el Ministro de Economía y Hacienda (o, con su habilitación expresa, por la Comisión Nacional del Mercado de Valores) y, en el mismo, 
que pretende ser reforzado también a través de la perspectiva integradora de la Responsabilidad Social Empresarial, a tenor de la última generación normativa promulgada, como - v.gr.- la Ley de Economía sostenible (LES) ${ }^{18}$, y proyectada, como el precitado Anteproyecto de Ley de Transparencia, que de forma expresa hace referencia a la exigencia de transparencia y a seguir un modelo de buen gobierno, junto a otras aportaciones realizadas en este sentido.

Completando lo mencionado en el anterior párrafo, y a tenor de la propia evolución sugerida con respecto al cumplimiento de dicho principio de transparencia, cabe significar el interés del legislador por reforzar su cumplimiento, ampliar su contenido y ámbito de aplicación y, en todo caso, asegurar su eficacia. En este sentido, podemos apreciar como el marco legal vigente -y proyectado- pretende incrementar el deber de información de las entidades/empresas, que en consecuencia deberán proceder, ofreciendo una

deberá ofrecerse una explicación detallada de la estructura del sistema de gobierno de la sociedad y de su funcionamiento. De este modo, resulta digno subrayar la delimitación legal (realizada por la LES) del contenido mínimo del informe de gobierno corporativo, así como los efectos de su inobservancia. Asimismo, la LES incorpora a la LMV el Artículo 61 ter: "Del informe anual sobre remuneraciones de los consejeros. Dicho informe deberá incluir información completa, clara y comprensible respecto a la política sobre remuneraciones de la sociedad aprobada por el Consejo para el año en curso, así como la prevista para años futuros. Este documento aportará el resumen global de cómo se aplicó la política de retribuciones durante el ejercicio, así como el detalle de las retribuciones individuales por cada uno de los consejeros. Además, esta política tendrá que haber sido difundida y sometida a votación, con carácter consultivo y como punto separado del orden del día, en las juntas generales de accionistas. La ley insta al Ministerio de Economía y Hacienda o, con su habilitación expresa, la Comisión Nacional del Mercado de Valores (CNMV). Sobre esta cuestión, vid., "Las compañias deberán elaborar un Informe Anual de Retribuciones: RSC. Las empresas cotizadas tendrán que informar de las retribuciones individuales de sus consejeros". Noticia publicada: 10/1/2011, en http://www.servimedia.es/Noticias/DetalleNoticia.aspx?seccion=24\&id=115164.

${ }^{18}$ Ley $2 / 2011$, de 4 de marzo de Economía sostenible (LES), BOE núm. 55, de 5 de marzo de 2011, es necesario señalar que la LES pretende fomentar la RSE, al respecto vid. artículos 35 y 39. De igual modo, la precitada Ley orienta el deber de elaborar y presentar un modelo de reporting "global e integrador"; con ello, podría afirmarse, se encamina un nuevo deber reporting no financiero, lo que demuestra un destacado avance, del modelo voluntario o de auto-regulación a un "renovado" modelo regulatorio básico (y, a su vez, compatible con la autoregulación). En este sentido, el artículo 39 LES -Promoción de la responsabilidad social de las empresas- determina que "las sociedades anónimas podrán hacer públicos con carácter anual sus politicas y resultados en materia de responsabilidad social empresarial a través de un informe especifico"; si bien, en todo caso las empresas (sociedades anónimas) con más de 1.000 empleados deberán de presentar (deber de comunicación) un Informe de RSE (específico) al Consejo Estatal de Responsabilidad Social de las Empresas (CERSE). Dichos informes han de seguir/cumplir los modelos oficiales o estándares internacionales reconocidos oficialmente. De igual modo, la LES determina que, en su caso, las entidades deberán acreditar si sus informes emitidos han sido objeto de verificación por tercera parte objetiva e independiente. 
información global (integrada); y, por tanto, con referencia a más aspectos, ampliando contenidos (aspectos financieros y también aspectos no financieros, como los referidos a cuestiones éticas, sociales y medioambientales, entre otras). Información más completa, clara y veraz, que periódicamente será suministrada por una entidad; ilustrando sobre de la cultura empresarial declarada y practicada por cada entidad: principios éticos y valores, políticas, modelo de buen gobierno y sistemas de gestión implementados. Con todo, se trata de hacer hincapié en el cumplimiento de la obligación de informar y comunicar sobre cada modelo de emprendimiento y su contribución social o colectiva ${ }^{19}$. De este modo, la RS se configura como un valor empresarial que permite identificar la función económica y social de una organización ${ }^{20}$, como un compromiso corporativo asumido y efectivamente practicado, que podrá ser objeto de evaluación, supervisión y control por parte de todos los (sus) grupos de interés. En suma, podemos afirmar que la RS adquiere un papel relevante en el marco de la información corporativa suministrada, configurándose dentro del propio ámbito jurídico de cumplimiento del "deber de transparencia".Y, por ende, la comunicación empresarial ha de responder a esta premisa, a efectos de evitar posibles riesgos legales y responsabilidades derivadas de un posible incumplimiento en el sentido expuesto.

${ }^{19}$ Al respecto, resultan de sumo interés las aportaciones de MONEVA ABADÍA, J.M. y LLENA MARACULLA, F., "Análisis de la información sobre Responsabilidad Social en las Empresas Industriales que cotizan en Bolsa", Núm. 87, Revista Española de Financiación y Contabilidad, Vol. XXVI, Abril-Junio, 1996, pp. 361-401, disponible en http://www.aeca.es/pub/refc/articulos.php?id=0351 (Última consulta realizada: 23-4-2012). MONEVA, J.M. "Información corporativa y desarrollo sostenible". №.106. Economistas, 2005, pp. 70-72. MONEVA, J.M., "El marco de la información social y medioambiental de la empresa: análisis de la Global Reporting Institute.", No. 30, Revista Interdisciplinar de Gestión Ambiental, 2001, pp. 1-15. VILLAGRA, N. "La RSC, su comunicación y la necesidad de una nueva conciencia", en BAJO. A. y VILLAGRA, N. (eds.), Reflexiones en torno a la responsabilidad social en el ámbito de la globalización. Madrid: Universidad Pontificia Comillas, 2008. pp. 127-143 pp.. VILLAGRA, N. “¿Por qué tenemos miedo a comunicar la Responsabilidad Social Corporativa?”, en BAJO, A. y VILLAGRA, N. (eds.), Evolución conceptual y práctica de una gestión responsable. Madrid: Universidad Pontificia Comillas, 2007, 77-92 pp.

${ }^{20}$ En este sentid, vid., los estudios de CHARLO, M. y MOYA, I. "El comportamiento financiero de las empresas socialmente responsables". Investigaciones Europeas de Dirección y Economía de la Empresa. Vol. 16-2, 2010,15-26 pp., y de BAJO, N. y DURAN, JJ. "Responsabilidad social y variables estratégicas en las grandes empresas españolas". Revista de Responsabilidad Social de la Empresa, n 2, mayo-agosto 2009, 51-77 pp. 


\subsection{CALIFICACIÓN DE LA RESPONSABILIDAD SOCIAL EMPRESARIAL}

Si bien, a priori, no resulta fácil consensuar una noción única de la terminología $\mathrm{RSC} / \mathrm{RSE}^{21}$, sí podemos admitir como interpretación más generalizada, en la actualidad, aquella comprensiva de su característica "triple dimensión" (económica, social y ambiental), siendo definida la RSC como "la integración voluntaria, por parte de las empresas, de las preocupaciones sociales $y$ medioambientales en sus operaciones comerciales y sus relaciones con sus interlocutores" (Comisión Europea, 2001) ${ }^{22}$. Al respecto, recientemente la Comisión Europea ha confirmado el interés por fomentar esta materia, destacando su relevancia para asegurar la sostenibilidad y competitividad de las empresas (tanto en el caso de las grandes empresas o multinacionales, como en el supuesto mayoritario de las medianas y pequeñas empresas, pymes $)^{23}$. En la práctica real,

${ }^{21}$ En este sentido, haciendo referencia a la dificultad de consensuar una noción unívoca, válida a todo a efectos prácticos, que sirva para proceder realizar una comparativa empresarial, se ha pronunciado María GJøLBERG señalando que "La RSE es un concepto esencialmente controvertido. (...) Para una confusión aún mayor, otros conceptos controvertidos, como el 'el desarrollo sostenible', la 'ciudadanía empresarial y la 'teoría de los accionistas', se suelen mencionar cuando se pretende crear una definición de la RSE. GJøLBERG, M. “¿Cuantificando lo incuantificable? Creación de un índice de prácticas de RSE y rendimiento de la RSE en 20 países". Revista de responsabilidad Social de la Empresa, mayo-agosto, nº 2, 2009, 15-51pp. (en concreto, cita referida en p. 21).

22 En este sentido, señalar que la interpretación actual del concepto actual de Responsabilidad Social Corporativa o Empresarial (RSC/RSE) ha de ser en un sentido amplio e integrador, comprensivo de todos sus factores $\mathrm{y}$ dimensiones (económica, social, medioambiental). Así, la Comisión Europea, en julio de 2001, publicó el Libro Verde sobre la RSE (COM, 2001, 366 Final): Fomentar un marco europeo para la responsabilidad social de las empresas, con el propósito de generar un marco europeo para el fomento de la RSE y, en concreto, plantear una estrategia comunitaria de promoción de la RSE. Siendo definida la Responsabilidad Social Empresarial como "la integración voluntaria, por parte de las empresas, de las preocupaciones sociales y medioambientales en sus operaciones comerciales y sus relaciones con sus interlocutores" (Cfr., FRANZONE, D., "Gobernanza Europea", en 'Gobernanza para el Desarrollo Sostenible', Cuadernos de Sostenibilidad y Patrimonio Natural, $n^{\circ} .7 / 2005$, Fundación Santander Central Hispano).

Sumado a lo anterior, conforme a la legislación vigente en España, la precitada Ley de Economía Sostenible (LES), -Ley 2/2011, de 4 de marzo.BOE núm. 55, de 5 de marzo de 2011, en relación con la Responsabilidad Social de las Empresas, (Capítulo VI del Título I), su artículo 39 reza de la Promoción de la responsabilidad social de las empresas, con el objetivo de incentivar la incorporación de políticas de RS en las empresas, y en especial a las PYMES.

23 En este sentido, los nuevos planteamientos propuestos en el documento titulado "Estrategia renovada de la Unión Europea para 2011-2014 sobre Responsabilidad Social de las Empresas (RSE)", Comunicación de la Comisión al Parlamento Europeo, al Consejo, al Comité Económico y Social Europeo y al Comité de Regiones, de 25 de octubre de 2011, COM 
cabe calificar a una empresa como socialmente responsable ${ }^{24}$ si adecuadamente ha integrado en sus políticas, objetivos, funciones y actuaciones, y de forma voluntaria $^{25}$ (esto es, además de los mínimos exigidos por la legislación vigente), un cuadro representativo de conductas y prácticas que contribuyan de forma eficaz a mejorar el entorno económico, social y medioambiental. Asumiendo, para ello, compromisos concretos, públicamente expresados, y con respecto a todos los (sus) grupos de interés. Dicha calificación, cada vez es más apreciada en el ámbito interno - europeo e internacional ${ }^{26}$, por lo que se procede -a dichos efectosaplicando distintas metodologías de valoración. No obstante, los métodos de valoración y calificación operan, en su mayoría, elaborando "índices de RSE" y, en algunos casos, evaluando las prácticas de RSE de distintas empresas, de forma

(2011) 681 final. Entre otras novedades previstas en este texto, de carácter no normativo, destacan: (a) Aporta una nueva definición de RSE. (b) Concreta compromisos europeos. (c) Realiza recomendaciones para las empresas europeas, diferenciando entre grandes empresas y pymes. Y, asimismo, realiza recomendaciones a los poderes públicos. Por último, (d) dicha Comunicación, informa sobre cómo encaminar la futura normativa europea en materia de transparencia informativa de las empresas y, en concreto, con referencia a las materias sociales y medioambientales.

${ }^{24}$ Sobre esta calificación y su significado, vid., OLCESE, A., RODRÍGUEZ, M.A. y ALFARO, J. Manual de la empresa responsable y sostenible. Madrid: McGraw-Hill, 2008, 321 y 322 pp. Por otra parte, TORTOSA señala que "la empresa socialmente responsable es aquella que, en sus actuaciones, asume la responsabilidad de producir un beneficio económico, social y medioambiental interna, externa y globalmente, tanto en su vertiente de dar cuentas como en su vertiente de dar respuesta (...)".(TORTOSA, E. "Responsabilidad social de la empresa: un nuevo modelo de empresa". Papeles de Economía Española, n $^{\circ} .108 .2006,106$ y ss. pp., en concreto p. 112).

${ }^{25}$ Al respecto, DURÁN HERRERA ha señalado (p.20) como se ha incrementado en los últimos años el número de empresas sensibilizadas por "la responsabilidad social estratégica", más allá de los mínimos legalmente exigidos. (DURÁN HERRERA, J.J. "Gobernanza, responsabilidad social y medioambiental de la empresa multinacional. Proceso estratégico", Revista de Responsabilidad Social de la Empresa, $\mathrm{n}^{\circ}$ 3, septiembre-diciembre 2009, 15-51 pp.).

${ }^{26}$ En este sentido, en el ámbito internacional, en los últimos años, han aumentado las iniciativas de colaboración empresarial en red, asociaciones sin ánimo de lucro que promueven aproximar la RSE/RSC, la implementación de la responsabilidad social y las acciones de emprendimiento social, insistiendo en la colaboración pública-privada en esta materia. Sirva de referencia al respecto, las iniciativas empresariales promovidas por BSR (red global de empresas para desarrollar estrategias y soluciones empresariales sostenibles) con el "Proyecto de Competitividad Responsable DR-CAFTA", proyecto de investigación para el diseño de políticas públicas que promueven y estimulan la RSE, que concentró en siete países, Brasil, Canadá, China, México, Perú, Suecia y Reino Unido. (ASCOLI, K. y BENZALEN, T., "Política pública y la promoción de la responsabilidad social empresarial", Escuela de Relaciones Internacionales y Estudios del Pacífico, San Diego (EE.UU.): Universidad de California. Agosto 2009. 1-10 pp., Disponible en http://drcafta.bsr.org/images/partners/Public_Policy_Promotion_of_CSR_final_traducido.pdf (Última consulta realizada el 23-4-2012). 
que se puedan ofrecer ordenadas por sectores de actividad, países, etc. Asimismo, como regla general, los citados índices examinan distintos aspectos (previamente definidos) y los datos suministrados al respecto, por ejemplo: "el informe sobre sostenibilidad, afiliación a organizaciones y redes de RSE, prácticas de certificación, además de diferentes evaluaciones del rendimiento de la RSE en la línea de base triple (...)"27 . Ahora bien, en ciertos supuestos, esta metodología utilizada puede resultar insuficiente, por adolecer de deficiencias, por no medir determinados factores considerados relevantes, como - v.gr.- el rendimiento o estimación de resultados concretos. En este caso, admitiendo posibles sesgos, no resultaría plenamente válida para apreciar la calidad y/o excelencia empresarial en términos de RSE respecto a una entidad objeto de evaluación. Si bien, sí puede resultar útil la aplicación de estas metodologías aceptadas con carácter general, en donde la RS operaría como "índice informativo": indicador informativo sobre las prácticas de RSE seguidas o practicadas. En este sentido, su funcionalidad quedaría demostrada, ofreciendo un marco de referencia en base a conjugar distintos datos y variables.

Por esta razón, en los últimos años, se ha tratado de mejorar la metodología empleada para analizar y "medir" las RSC en las empresas; a dicho fin, se trabaja en la mejora y el perfeccionamiento de los modelos de calificación y los índices de RSE ofrecidos/aplicables. En este sentido, cabe destacar -entre otras- nueve iniciativas o modelos en materia de evaluación de la RSE (aplicables con base en cuatro categorías de indicadores de referencia a escala global), que aportan calificaciones de interés, a saber: (i) calificaciones conforme al criterio de la inversión socialmente responsable realizada por las distintas compañías (Índice de Sostenibilidad Dow Jones, FTSE4Good y el listado ofrecido por el "The Global 100 Most Sustainable Corporations"); (ii) calificaciones atendiendo a la pertenencia a asociaciones/club o/y redes de RSE (UN Global Compact y World Business Council for Sustainable Development); (iii) calificaciones sobre realización de prácticas de información en sostenibilidad (encuestas KPMG Sustainability Reporting Survey y, por otra parte, los estándares GRI-Global Reporting Initiative); y (iv) calificaciones conforme a sistemas internacionales de certificación en materia de gestión medioambiental, $v . g r$., conforme a la norma técnica internacional ISO 14001 (certificable) y/o al Reglamento europeo EMAS (Reglamento (CE) $n^{\circ}$ 1221/2009 del Parlamento europeo y del Consejo de 25 de noviembre de 2009, relativo a la participación voluntaria de organizaciones en un sistema comunitario de gestión y auditoría medioambientales, EMAS. DOUE L 342 , de 22-12-2009).

${ }^{27}$ CAÑIBANO, L."Cambios en la información financiera de la empresa española”, $X X V$ Años de Contabilidad Universitaria en España, 85-130 pp., CAÑIBANO, L. y SANCHEZ, P., "Measurement, Management and Reporting on Intangibles: State of the Art", Readings son Intangibles and Intellectual Capital. Madrid: AECA, 2004. 
Hay que añadir a lo mencionado, y de forma específica, la referencia a la norma internacional ISO $26000^{28}$ (norma-guía RSC, no certificable), operando como una guía modelo internacional en materia de $\mathrm{RSE} / \mathrm{RSC}$. Al respecto, existen otros estándares europeos, como el establecido por la norma europea SGE 21, que fija un conjunto de requisitos que han de cumplirse para asegurar la integración de la gestión de la Responsabilidad Social en la estrategia corporativa ${ }^{29}$. Por otra parte, desde una perspectiva técnica y jurídica, resulta oportuno hacer hincapié en los nuevos instrumentos para declarar, documentar y registrar el compromiso y los desempeños practicados en materia de RSE (v.gr., elaboración y emisión/publicación de Memorias de Sostenibilidad, analizadas infra), al servicio del principio de la transparencia informativa y por tanto como un requerimiento técnico cualitativo exigible a todo tipo de entidad u operador en el mercado.

\subsection{GESTIÓN DE LA INFORMACIÓN CORPORATIVA}

En todo caso, conforme a lo expuesto en los apartados precedentes, la gestión de la RSE queda vinculada a otro aspecto de interés para las organizaciones: la gestión estratégica de la reputación corporativa; $y$, desde este enfoque será necesario adecuar -de forma estratégica- los sistemas de información y comunicación de la RS practicada por una entidad, propiciando la generación de una percepción positiva por parte de los grupos de interés más significativos o estratégicos. Este proceder redundará en interés propio (de la propia empresa) y también colectivo (entorno social y ambiental), sirviendo para consolidar e incrementar la reputación corporativa y, con ello, obtener ventajas competitivas ${ }^{30}$. La reputación implica distinción selectiva en un entorno global competitivo (valor reputacional), mas no es suficiente -a dicho fin- con lograr "una buena imagen", por cuanto la "imagen de la marca corporativa" puede ser algo efímero; por esta razón, la reputación -optimizar su gestión- es la que aportará a aquélla solidez y garantía de mantenimiento en el tiempo y espacio. Sumado a lo anterior, hay que señalar que hoy la gestión de la reputación corporativa está ligada a demostrar una

${ }^{28}$ SÁEZ GALlEGO, C., "La Guía ISO 26000: Facilitando la adopción de prácticas responsables en la empresa", Revista de la Responsabilidad Social de la Empresa, $\mathrm{n}^{\circ}$. 7, eneroabril 2011, texto disponible en http://www.fundacionluisvives.org/rse/digital/7/articulos/60025/ index.html (Consulta realizada: 23-4-2012).

${ }^{29}$ Vid., HERRERO HERNANDEZ, A., "La gestión de la responsabilidad social. El sistema de gestión ética y socialmente responsable propuesto por la SGE 21", Revista de Responsabilidad Social de la Empresa, mayo-agosto 2009, 199-207 pp. Contenidos y actualizaciones con respecto a la norma SGE 21 en www.foretica.org/conocimientorse/estandares/sge-21?lang=es (última consulta realizada: 23-4-2012).

${ }^{30} \mathrm{Al}$ respecto el artículo de CARRILLO DURÁN, M.V. y NUÑO MORAL, M.V. "La documentación en la evaluación y gestión de la imagen corporativa". El profesional de la información, vol. 19. $\mathrm{n}^{\circ} .2$, marzo-abril 2010,123-131pp. 
conducta empresarial responsable, tal y como hemos mencionado previamente. Por ende, no consiste sólo en emplear herramientas de marketing a efectos de propiciar técnicas de "lavado de imagen", ni debe ser abordada persiguiendo simples efectos ornamentales o publicitarios sin contenido real. Todo lo contrario, la entidad ha de disponer de una autentica gestión estratégica de la comunicación corporativa para preservar su reputación. Lo cual, implica cumplir plenamente, y a todos los efectos, con todos los principios/dimensiones propios de la RSE/RSC ${ }^{31}$, siendo la comunicación corporativa el principal vehículo conductor del hito reputacional a lo largo de la propia evolución y ciclo vital de una organización. A su vez, reconociendo que el cumplimiento del principio de transparencia informativa es relevante -y no solo a efectos legales-, cabe afirmar que, en este marco, resulta esencial la implementación de estrategias y programas de comunicación interna / externa específicos y eficaces, mantener canales que permitan la proactividad entre organización y (sus) grupos de interés (garantizando la participación activa todas las partes implicada y la retroalimentación). En este sentido, los responsables de RSE y/o los responsables de Comunicación de las compañías, apoyados por la Alta dirección de la entidad, tienen un papel fundamental en el ámbito de la gerencia de la reputación corporativa vinculándola a la RSC.

\section{COMUNICACIÓN DE LA RESPONSABILIDAD SOCIAL (RS)}

Tal y como se ha reconocido, la responsabilidad social como intangible es un valor hoy muy estimado por el mercado y la sociedad, por ende, ha de ser ejercitada atendiendo a compromisos declarados públicamente por cada operador/entidad empresarial (comunicado, v.gr., vía reporting). Dicho "compromiso en responsabilidad social", una vez declarado públicamente $-\mathrm{y}$ siendo así demostrado en la práctica- permitirá alcanzar y mantener una determinada reputación, que puede ser requerida en especial por los inversores, las autoridades y la sociedad en general (por todos los grupos de interés de una organización). Como tal, también puede ser exigible -en reciprocidad- a otras organizaciones/empresas con las que una entidad proyecte relaciones jurídicas, acuerdos/convenios u otro tipo de alianzas; en este sentido, instrumentos como la Due Diligence ${ }^{32}$ y la Compliance ${ }^{33}$ son cada vez más utilizados, para poder obtener

31 Resulta claro que la Responsabilidad social permite a las empresas destacarse, diferenciarse frente a sus competidores, refuerza la imagen de marca y la consecución de un importante mejora de su reputación corporativa; por tanto, como se afirma de forma expresa "planteársela como estrategia e empresa puede ser rentable", ALMELA BURGOS, J.M. "La implantación de la RSC, paso a paso". Estrategia Financiera, n. ${ }^{\circ} 257$. enero 2009, 34-39 pp.

${ }^{32} \mathrm{Al}$ respecto, ROSENBLOOM, A.H. Due Diligence. La guía perfecta para fusiones y adquisiciones, asociaciones en participaciones, alianzas estratégicas. México, D.F.: Limusa- 
información corporativa y evaluar -o "diagnosticar"- a los candidatos, con la finalidad de seleccionar al idóneo.

En consecuencia, conforme a esta consideración del "valor reputacional" de la RSC, amén de su valoración técnica y jurídica, resultará esencial avanzar en la mejora del diseño y de los contenidos ofrecidos por los actuales Reporting o Informes de RSC/RSE o/y Memorias de Sostenibilidad Empresarial, configurados hoy como piezas clave de los sistemas de información y medios de comunicación corporativa $^{34}$, por cuanto permiten suministrar una información global e integradora ( $v . g r$., informar sobre políticas, objetivos, compromisos, procesos y resultados, y asimismo para demostrar los progresos logrados en este ámbito).

\section{INFORMES DE SOSTENIBILIDAD (SUSTAINABILITY REPORT)}

La memoria de sostenibilidad o informe de responsabilidad social es un tipo de informe empresarial en el que cada entidad describe su desempeño en materia económica, ambiental y social. Elaborado y emitido periódicamente, será publicado por la organización, por lo general con carácter anual o bianual. En dicho tipo de informe se declaran los principios, políticas y objetivos, asimismo se exponen las actuaciones de la organización en tres ámbitos destacados: económico, social y ambiental, aportando información sobre los resultados alcanzados, las mejoras propiciadas y los retos proyectados. Supone, por tanto, un destacado ejercicio de transparencia, permite la autoevaluación y además la evaluación por parte de terceros. De igual modo, ofrece -y desde el inicio del proceso de elaboración- un interesante y oportuno canal de comunicación con todos los grupos de interés de una entidad, siendo además una declaración expresa y pública de compromiso. A su vez, permite comparar la actuación y la responsabilidad entre empresas. Con todo, los denominados Informes de RSC/RSE-Memorias de sostenibilidad $^{35}$ de una entidad $u$ organización son

Noriega Editores, S.A., 2005. PASTRANA PIÑA, J.M. "Modelo de auditoría legal ('due diligence') en operaciones de adquisición societaria". $R d S$, n $\mathrm{n}^{\mathrm{o}} .34,2010-1,295-302$ pp.

${ }_{33}$ Compliance es la función que permite evaluar el grado de cumplimiento normativo observado por una entidad. Por tanto, es hoy un medio oportuno para diagnosticar, considerar y potenciar el cumplimiento de compromisos y la sostenibilidad empresarial. Al respecto, Allianz Seguros: "Gestión de Riesgos y Compliance, ¿Dos caras de una misma moneda?". Ponencia presentada en el XXI Congreso Español de Gerencia de Riesgos y Seguros, Madrid: AGERS, 26 de mayo de 2010.

${ }^{34}$ Citar como ejemplo, GRI (Global Reporting Initiative) publica una nueva guía para asegurar la mayor transparencia y responsabilidad de los medios de comunicación, "La nueva guía GRI's Media Sector Supplement ha sido presentada en la conferencia del Día Internacional de la Libertad de Prensa organizada por la UNESCO", disponible en http://www.corresponsables.com/printpdf/174080 (Consulta: 4-5-2012).

${ }^{35}$ En esta materia, resultan de sumo interés los trabajos de NIETO, M. "Difusión de la 
instrumentos de reporting aplicables en cualquier organización o empresas, y responden a la implementación de sistemas de autoevaluación y autodeclaración adoptados por una entidad. En la actualidad, son una herramienta básica de comunicación e información empresarial, de gran interés para cualquier tipo de organización, cualquiera que fuera su naturaleza jurídica, su sector operativo, su dimensión y/o volumen de negocio. Si bien, en principio, estos informes son de carácter voluntario, se trata de valiosos medios documentales, instrumentos que permiten a una organización dar cuenta pública de sus actuaciones económicas, sociales y medioambientales en relación a sus operaciones, productos y servicios. Al respecto, cabe citar como ejemplo los elaborados conforme al modelo o estándar internacional $\mathrm{GRI}^{36}$, que permite conocer e interpretar cómo una entidad afronta su actividad y se relaciona, cómo orienta y aplica su política, materializa su cultura empresarial y la transmite (sirviendo de ejemplo y distinguiéndose en un determinado sector económico y/o en el mercado), determina estrategias y cumple programas, desarrolla su negocio, presta servicios, traza y encamina proyectos futuros, entre otros aspectos de interés. Así, las memorias de RSE - informes de sostenibilidad son reconocidas fuentes -accesibles- para informar y documentar la responsabilidad corporativa operada por una organización (RSC/RSE).

responsabilidad social corporativa en la empresa española". Economistas, nº.106. 2005, 32 y ss. pp. MONEVA, J.M. "Mecanismos de verificación de la información sobre responsabilidad social corporativa". Papeles de Economía Española, nº.108. 2006, 75 y ss. pp.

36 GRI: modelo-guía Global Reporting Initiative, GRI (2002), p.1. Global Reporting Initiative: Sustainability Reporting Guidelines (http://www.globalreporting.org). La guía GRI nace en 1997 como una iniciativa impulsada por el Programa de Medio Ambiente de las Naciones Unidas (PNUMA) y de la Coalition for Environmentally Responsible Economies (CERES), con objeto de fijar un modelo y orientar para que las empresas pudieran informar sobre su actuaciones en el ámbito del desarrollo sostenible. La primera guía elaborada y publicada fue la GRI 2000 y, siendo ésta revisada y actualizada, se procedió a proporcionar una segunda versión del modelo la GRI 2002 -cuya presentación en agosto 2002 coincide con la Cumbre Mundial sobre Desarrollo Sostenible (Rio+10), celebrada en Johannesburgo-. Al respecto, MONEVA, J.M. "Información corporativa y desarrollo sostenible". Economistas, n ${ }^{\circ}$ 106, 2005, 70-72 pp. Posteriormente, igualmente tras un proceso de revisión y actualización, se publicó una nueva guía GRI 2006 (GRI 3) con destacadas modificaciones respecto a la anterior. Siendo hoy el modelo de referencia. En todo caso, conviene recordar que esta guía estándar opera como prototipo y, al mismo tiempo, modelo orientativo; por ello, es aconsejable que cada organización diseñe e implemente su propio esquema. Del citado autor son de gran interés varios artículos publicados sobre esta temática, como "El marco de la información social y medioambiental de la empresa: análisis de la Global Reporting Institute", Revista Interdisciplinar de Gestión Ambiental, n³0, 2001,1-15 pp. "La información sobre responsabilidad social de la empresa en el contexto de la reforma contable", en Responsabilidad Social Corporativa. Aspectos jurídico-económicos. Castellón: Universidad Jaume I, 2004, 181211 pp. MONEVA, J.M., LLENA, F. y LAMEDA, I. "Calidad de los informes de sostenibilidad de la empresa española", comunicación en el XIII Congreso de la Asociación Española de Contabilidad y Administración de Empresas (AECA), Oviedo, septiembre 2005. 


\subsection{CONTENIDO BÁSICO DE LOS INFORMES DE RSC/RSE}

En este sentido, en la actualidad, existen distintos modelos internacionales o estándares para la elaboración de las Memorias de Sostenibilidad. Entre los diversos métodos y guías hoy seguidos, la más reconocida es la desarrollada por Global Reporting Initiative $\left(\mathrm{GRI}^{37}\right)$. Estos reporting -informes- están basados en los tres enfoques y aspectos del concepto de desarrollo sostenible (desarrollo económico, respeto al medioambiente y desarrollo social), conforme al clásico enfoque de información Triple Bottom Line (TBL) -triple balance o triple cuenta de resultados $-{ }^{38}$. Es necesario apuntar que durante el período comprendido entre los años 2002-2006, la organización GRI preparó, procurando el consenso entre las partes interesadas, la tercera versión de la guía GRI, publicándose la versión actual denominada GRI 3 (2006). Con ello, se ha tratado de aportar un modelo de aplicación más flexible, una guía más operativa, en la que se tratan de mejorar calidad de la información suministrada. Asimismo, fomentar y orientar el desarrollo de los actuales "informes de RSE" o sostenibilidad, con un claro propósito: propiciar la extensión de su práctica y, del mismo modo, perfeccionar la elaboración y publicación de informes de Responsabilidad Corporativa, obteniendo informes más "relevantes, comparables, verificables y enfocados en el desempeño de las organizaciones" ${ }^{39}$. El actual estándar G3 se ordena conforme a dos bloques objetivos diferenciados: el primero, configurado por los Principios y orientaciones para la elaboración de los informes que sigue la organización; y, el segundo, ofreciendo los Contenidos básicos (perfil, enfoque de gestión e indicadores de desempeño).

${ }^{37}$ GRI: Global Reporting Initiative. Al respecto destacar, Memories of Sustainability of Global Reporting Initiative, las realizadas conforme a los indicadores internacionales GRI 3 (Global Reporting Initiative, disponible en www. globalreporting.org). Al respecto, BLASCO, J.L. y SÁEZ GALLEGO, C. "Global Reporting Initiative, La historia de un éxito". Revista de Responsabilidad Social de la Empresa, nº.3, septiembre-diciembre 2009, 191-201 pp. En la actualidad, la GRI 3 (2006) establece las orientaciones aplicables para la preparación del documento y su proceso de actualización, como la participación de los grupos de interés de la compañía, insistiendo en el rigor y la exhaustividad; al mismo tiempo, permitiendo su aplicación flexible, establece tres niveles de exigencia e la información proporcionada. Asimismo, indica los contenidos que debe incluir la memoria, conforme a unas categorías ordenadas de indicadores y además establece unos principios y orientaciones para su aplicación durante el proceso de preparación del documento. Del mismo modo, orienta sobre el proceder mediante comprobaciones recomendadas, entre otras cuestiones de interés. Al respecto, vid., CAÑIZARES, J. "Entidades responsables", UNE La revista de AENOR, n.248. abril, 2010, 48-51 pp.

${ }^{38}$ Cfr., ELKInGTON, J. Cannibals With Forks: The Triple Bottom Line of 21st Century Business, Oxford: Capstone, 1997. s

${ }^{39}$ Cfr., BLASCO, J.L. y SÁEZ GALLEGO, C. "Global Reporting Initiative, La historia de un éxito". Revista de Responsabilidad Social de la Empresa, $\mathrm{n}^{\circ} .3$. septiembre-diciembre 2009, 191-201 pp. (en concreto, cita pp. 192 y 193). 
Sumado a lo anterior, la guía aporta una serie de protocolos y complementos sectoriales a los efectos prácticos de facilitar a las organizaciones en su proceso de informar sobre responsabilidad corporativa (posteriormente referidos). En la actualidad, se ha producido un incremento en el número de informes emitidos en materia de responsabilidad corporativa de las organizaciones; con ello, puede confirmarse que la mayoría de las principales empresas nacionales e internacionales sí emiten estos reporting con la debida regularidad; además, algunas de las compañías han innovado en sus proceso de elaboración, modelos, contenidos ofrecidos y comunicaciones publicadas al respecto ${ }^{40}$. No obstante, a futuro, convendrá perfeccionar dichos modelos, ofreciendo Memorias de RSE y Sostenibilidad más completas, pues todavía son pocas las entidades que abordan esta cuestión con la relevancia que se requiere ${ }^{41}$.

Con todo, en el presente, la Unión Europea pretende incrementar los requerimientos informativos exigidos con respecto a los requerimientos no financieros, aportando recomendaciones y fomentando el uso de guías facilitadoras, y destacando aquellos aspectos que se deben ser considerados relevantes $^{42}$. Conforme a dicha motivación, se tratará de promover $\mathrm{y}$, a su vez,

${ }^{40}$ Cfr., "Estudio de KPMG International sobre Informes de Responsabilidad Corporativa 2008". Idem, Estudio 2011. (http://www.kpmg.es. Consultada: 3-5-2012).

${ }^{41}$ Sobre esta cuestión, la Unión Europea realizó una consulta pública, para conocer la opinión y valorar la información que debe ser suministrada por las empresas con respecto a los aspectos no financieros y en base a la consideración de los principios generales marcados por la GRI (Global Reporting Initiative), conforme a los documentos del Global Compact (Pacto Mundial de las Naciones Unidas) y las Directrices de la OCDE, asimismo de la norma técnicaguía de RSE ISO 26000, entre otras guías, modelos o estándares internacionales aplicables en esta materia. De igual modo, se ha constituido en la Comisión Europea un Grupo de Expertos sobre Comunicación de la Información No Financiera, integrado por representantes de empresas, inversores, consumidores, auditores y agencias de ratings, académicos y organizaciones que trabajan en esta materia, para proponer mejoras en la elaboración y contenidos de los Informes que deben ofrecer en esta materia las empresas, $c f r$., Comisión Europea, Internal Market and Services DG (Free Movement of Capital, Company Law and Corporate Governance): Summary Report of The Responses Received to The Public Consultation on Disclosure of Non-Financial Information by Companies Directorate General for The Internal Market and Service. April 2011. Executive Summary (EU), disponible en http://ec.europa.eu/internal_market/consultations/docs/2010/non-financial_reporting/summary_ report_en.pdf (última consulta realizada: 23-4-2012). Entre otros resultados ofrecidos por esta consulta realizada, se muestra que es necesario aportar una mejor y más completa información referente a los aspectos no financieros. Por ende, se constata la oportunidad de ofrecer informes integrados como herramienta útil a la hora de poder valorar la conducta empresarial.

42 Cfr., Comunicación de la Comisión al Parlamento Europeo, al Consejo, al Comité Económico y Social Europeo y al Comité de las Regiones, "Estrategia renovada de la Unión Europea para 2011-2014 sobre Responsabilidad Social de las Empresas (RSE)", de 25 de octubre de 2011. COM (2011) 681 final. Disponible en www.eur-lex.europa.eu (Fecha de consulta: 26/3/2012). 
generar "herramientas" y medios más eficaces, documentos para el control público y, por ende, para la "rendición pública de cuentas" "43 accesibles en la práctica real, a disposición de todos los grupos de interés de una organización.

Por tanto, en la actualidad, cabe afirmar que la publicación de una Memoria de Sostenibilidad por parte de una entidad, -por ejemplo, realizada conforme al modelo básico o actual guía GRI -Global Reporting Initiative (o GRI 3)-, aportará destacadas ventajas, entre otras:

(a) Constituye una potente herramienta de comunicación en materia de RSE y mejora las relaciones de la empresa con su entorno. Al mismo tiempo, (b) es un interesante "soporte" para observar y proceder a la revisión-actualización del modelo de gerencia empresarial de la compañía y en relación con la integración efectiva de la RSE y, de igual modo, de todos los aspectos y "dimensiones" que la misma incluye. (c) Incentiva que las organizaciones gestionen su RS de forma eficiente. Estableciendo mecanismos adecuados para "nutrir" y retroalimentar los contenidos ofrecidos/publicados en este ámbito, conforme a los datos y la revisión/actualización periódica que precisa la guía GRI (por ejemplo). Todo ello, deberá ser analizado con el máximo rigor y diligencia, pues ha de ofrecerse un reporting veraz, congruente y creíble, en todos sus extremos. Además, dicho reporting -una vez realizado- deberá quedar "predispuesto" para facilitar su "examen" o validación por tercera parte independiente (auditoría/verificación o, en su caso, certificación). Asimismo, dicho rigor puede combinarse con la flexibilidad permitida por GRI, permitiendo su adecuada implementación, en atención a cada caso concreto de entidad. En este sentido, básicamente el modelo GRI sigue las premisas básicas de todo sistema de gestión de la calidad, conforme a seguir un proceso de mejora continua, orientado a los resultados, hacia la alta calidad y la excelencia. El modelo GRI, al igual que otros estándares voluntarios, ofrece la adhesión y el compromiso de cumplimiento/aceptación conforme a distintos niveles de exigencia determinados por GRI, lo que favorece su aplicación, respetando el ritmo de la propia dinámica de los procesos de cada compañía. De igual modo, permite su revisión y actualización periódica (por lo general, anual) de sus contenidos y progresos.

Con respecto al contenido básico de las memorias o informes, conforme a la GRI, hay que señalar que, para elaborar este tipo de documentos, cada entidad debe incluir y ofrecer una información completa sobre distintos ámbitos predeterminados, a saber: (i) Estrategia y perfil: ofrece información general sobre la entidad (v.gr., mercados, productos, estructura de gobierno corporativo y líneas estratégicas). (ii) Enfoque de gestión: ofrece información sobre el enfoque dado

\footnotetext{
${ }^{43} \mathrm{Al}$ respecto, opiniones aportadas por BLASCO VÁZQUEZ, J.L. y ELORTZ ARTEGA, I. "Informes de responsabilidad corporativa: la historia de un éxito". Estrategia Financiera, $\mathrm{n}^{\mathrm{o}}$.257. enero, 2009, 26-29 pp.
} 
por la organización con respecto a las distintas materias/áreas, exponiendo como se abordan cuestiones, aspectos o temas concretos y dentro del contexto correspondiente o área específica. (iii) Indicadores de desempeño (cualitativos y cuantitativos): permiten la comparación de los datos e información proporcionada sobre el desempeño económico, social y ambiental de la organización. A su vez, la GRI se complementa con otros documentos ofrecidos, destacando dos: los Protocolos de los indicadores y las Guías sectoriales ${ }^{44}$. De este modo, observando cómo una entidad procura la sostenibilidad en la práctica y su evolución al respecto, será posible mediante estos indicadores comparar la situación y el progreso de una entidad con otros supuestos. Asimismo, cada uno de los indicadores de desempeño marcados dispone de una serie de Protocolos que aportan definiciones y orientan sobre cómo proceder a obtener y recopilar los datos que han de suministrase; además, ofrecen otras recomendaciones útiles para proceder a la interpretación y adecuada aplicación del modelo -estándar- por cada organización ${ }^{45}$. Ahora bien, los modelos de guías, métodos e indicadores,

${ }^{44}$ Los referidos "complementos adicionales" a la guía base GRI 3 se encuentran disponibles en www.globalreporting.org. Existen en la actualidad dos guías - suplementos sectoriales elaborados en su versión final y publicados, dedicados a Electricidad y Servicios Financieros. Además, en preparación -se encuentran en fase de borrador- otras guías sectoriales y complementarias.

${ }^{45}$ Con respecto al contenido de la memoria, precisar sus distintas partes: una parte dedicada a la visión que la compañía u organización mantiene sobre el desarrollo sostenible; otra, contiene su perfil y una serie de indicadores económicos, ambientales y sociales ordenados en principales y adicionales o complementarios. Indicadores que facilitan la correcta interpretación de los datos y su comparación. Por otra parte, en interés de permitir una aplicación flexible del modelo GRI, la guía ofrece tres niveles de exigencia con respecto a la información aportada y su nivel de aplicación y seguimiento (A, B y C). A tal efecto, sumado a lo anterior, se puede obtener la calificación "+", a través del someter el reporting a un proceso de la verificación externa, y así obtener como valor añadido la calificación de $\mathrm{A}+, \mathrm{B}+\mathrm{C}+$. De este modo, sintetizando, indicar que alcanzar el nivel C sólo precisa aportar información sobre algunos puntos de los apartados 1, 2, 3 y 4 de la GRI, en concreto: Estrategia y análisis; Perfil de la organización, Parámetros de la memoria y gobierno, Compromisos y participación de los grupos de interés; además, seguir un mínimo de 190 indicadores de desempeño, incluyendo al menos uno de cada dimensión: económica, ambiental y social. El siguiente nivel en exigencia es el $\mathrm{B}$, que requiere completar todos los puntos de los precitados apartados $1 \mathrm{a} 4 \mathrm{y}$ asimismo un mínimo de 20 indicadores de desempeño que, al menos, incluyan uno de cada una de estas áreas: económica, ambiental, derechos humanos, prácticas laborales y ética del trabajo, sociedad y responsabilidad sobre los productos/servicios. El nivel A requiere cumplir todos los puntos e indicadores de la Guía, o, en su defecto, señalar los motivos de omisiones o, en su caso, correcciones operadas con respecto a un indicador. Añadir a lo expuesto, que estos tres niveles (A, B y C) suponen, en principio, una autodeclaración por parte de la empresa (mantienen ese valor y efecto); ahora bien, pueden ser objeto de una auditoría independiente, siendo validados. Así, una organización podrá operar y remitir su informe a la organización GRI a través de su página web, declarando que su memoria alcanza un determinado nivel (A, B 
precitados -conforme al modelo GRI- y, en la práctica, la elaboración de estas memorias o reporting por las compañías plantean todavía algunos problemas ${ }^{46}$, enfrentando retos destacados. Entre otros, cabe señalar el lograr alcanzar una plena integración de la información ofrecida sobre la responsabilidad corporativa y la gestión de riesgos en los informes anuales convencionales de gobierno corporativo emitidos por las entidades/empresas; pues, al respecto, hay que decir que en algunos países, entre ellos España, dicha práctica -más allá de los requerimientos exigidos a las sociedades cotizadas conforme a la legislación específica vigente (referida en el segundo de este trabajo, vid., nota pie de página $n^{\circ} .17$ )- no viene siendo un proceder típico ni habitual en el ámbito de las pequeñas y medianas empresas (pymes), pese a ser éste un segmento mayoritario y representativo del tejido empresarial europeo ${ }^{47}$.

o C), de tal modo que GRI procederá, previa comprobación del nivel declarado, a recoger en su registro la denominación/calificación y ofrecer los enlaces a los informes que les envían las distintas organizaciones/empresas. En todo caso, señalar que el nivel aceptado únicamente podrá adoptar la calificación "+" -indicando una mayor cualificación, conforme se ha expuesto aquí- si efectivamente así ha sido verificado por un profesional acreditado o entidad independiente. Al respecto, exponiendo metodología GRI 3, vid., CAÑIZARES, J.: "Entidades responsables", UNE La revista de AENOR, n 248/abril 2010, pp. 48-51.

${ }_{46} \mathrm{De}$ forma específica, haciendo referencia al marco actual de la información corporativa sobre RS e ilustrando sobre nuevos proyectos elaborados en materia de ofrecer un cuadro de indicadores - estándares generales y herramientas fiables para el tratamiento de la información $\mathrm{y}$, a su vez, apuntando las necesidades observadas en la práctica de suministrar información sobre RSC, vid., LIZCANO ÁLVAREZ, J.L., GARCÍA SÁNCHEZ, I. y FERNÁNDEZ BLANCO, A. Normalización de la Información sobre Responsabilidad Social Corporativa. $\mathrm{N}^{\mathrm{o}}$ 7, Documento AECA. Madrid: AECA, Asociación Española de Contabilidad y Administración de Empresas (AECA), octubre 2010.

47 Señalar que en nuestro país el primer informe de RSC fue publicado en el año 2001, inspirándose en los informes ambientales o en materia de gestión medioambiental. Confirmar que, como se ha proclamado, en el momento actual "España es el cuarto país en número de informes de RSC. Esta cantidad ha aumentado en un 136\% desde 2005. El porcentaje de información presentada en materia de responsabilidad corporativa en España se sitúa por encima de la medida en todos los sectores del estudio (...). La integración de la información sobre responsabilidad corporativa en los informes anuales convencionales está aún lejos de ser algo habitual en España. Un tercio de las compañías estudiadas no informa sobre responsabilidad corporativa en absoluto, mientras que aproximadamente una tercera parte publica un informe de responsabilidad corporativa, por separado de sus informes anuales. España ocupa un puesto destacado en cuanto al número de compañías que someten sus informes a verificación externa, situándose en la cabeza del grupo de entre los países estudiados". BLASCO VÁZQUEZ, J.L. y ELORTZ ARTEGA, I. "Informes de responsabilidad corporativa: la historia de un éxito".. Estrategia Financiera, no 257 enero 2009, 26-29 pp. (cita referida en p. 28). 


\section{COROLARIO}

En suma, cabe afirmar que -en la actualidad y a futuro- las entidades u organizaciones, cualquiera que fuera su tipología y naturaleza jurídica, deben saber integrar los principios de RSC/RSE en su modelo de organización, gobernanza y sistema de gestión, para de este modo poder posicionarse estratégicamente en el mercado global. La integración de la RS permitirá a la organización alcanzar de una forma satisfactoria sus propios objetivos y pretensiones competitivas; y, sobre todo, "responder" a las expectativas de los grupos de interés más significativos. Al respecto, las reivindicaciones sociales actuales demandan conductas empresariales más responsables y sostenibles, en el mismo sentido los mercados financieros; por ende, una compañía podrá alcanzar y/o mantener una calificación y reputación corporativa positiva si actúa en consecuencia con dichas exigencias.

A su vez, la reputación empresarial depende en buena medida de cómo es valorada la acción y relación que una entidad empresarial mantiene con su entorno (social, ambiental,...), más allá del debido cumplimiento regulatorio o normativo vigente. De este modo, el informar adecuadamente sobre el emprendimiento económico, social y medioambiental se convierte en una cuestión estratégica clave, para cualquier organización que opere en el ámbito interno-europeo e internacional, demostrando su contribución al respecto. Por esta razón, los Informes de RSC/RSE y/o las Memorias de Sostenibilidad han adquirido un destacado valor documental, siendo auténticas fuentes de información para conocer y evaluar el compromiso y la responsabilidad empresarial, su evolución, mejoras operadas, entre otras cuestiones. En todo caso, las buenas prácticas emprendidas en materia de RS deben ser adecuadamente comunicadas (interna y externamente) por la organización $y$, asimismo, podrán ser objeto de verificación por tercera parte independiente.

Por este motivo, las técnicas de reporting corporativo en materia de RSC/RSE o RS- se configuran como herramientas estratégicas básicas, auténticas fuentes del conocimiento empresarial, que deben ser accesibles a todos los interesados, siendo periódicamente actualizadas y congruentes con la propia dinámica de la organización y su entorno. En consecuencia, por su alto valor documental, resulta preciso proceder al perfeccionamiento de este tipo de documentos, completar la integración de la información ofrecida (global), referida tanto a los aspectos financieros como, de forma específica, a los no financieros, que ha de suministrar cada entidad u operador. De igual modo, podrá resultar conveniente articular sistemas oficiales de evaluación y verificación al respecto. En este sentido, las medidas para reforzar la transparencia informativa pueden ser un camino apropiado para acometer dichos perfeccionamientos, conforme a las recomendaciones europeas e internacionales. Con todo, en el momento presente, todo tipo de organización ha de saber integrar en su planificación estratégica un 
plan director (business plan) o programa específico de RSC/RC, que en todo caso considerará la elaboración y emisión periódica de Reporting de RSE y/o Memorias de Sostenibilidad, como medios idóneos para facilitar la evaluación y, a su vez, la adecuada comunicación del modelo de emprendimiento seguido y/o proyectado por una entidad en cada caso.

\section{BIBLIOGRAFÍA}

ALMELA BURGOS, J.M. "La implantación de la RSC, paso a paso". Estrategia Financiera, $\mathrm{n}^{\circ}$ 257, enero 2009, pp 34-39.

ASCOLI, K. y BENZALEN, T. "Política pública y la promoción de la responsabilidad social empresarial". San Diego: Escuela de Relaciones Internacionales y Estudios del Pacífico, Universidad de California. Agosto 2009. 1-10 pp. Disponible en http://www.drcafta.bsr.org/images/partnes/Public _Policy_Promotion_of_BSR_ final traducido.pdf (Consultada: 26/3/2012).

BAJO, $\overline{\mathrm{N}}$. y DURAN, JJ. "Responsabilidad social y variables estratégicas en las grandes empresas españolas". Revista de Responsabilidad Social de la Empresa, $\mathrm{n}^{\circ}$ 2, mayo-agosto 2009, pp.51-77.

BAJO SANJUÁN, A. y VILLAGRA GARCÍA, N. Valores para una gestión socialmente responsable. Memoria Académica Curso 2008-2009, Cátedra Javier Benjumea (Focus-Abengoa). Memoria Académica/6. Madrid: Universidad Pontifica Comillas, 2009, pp.160-161.

BLASCO, J.L. y SÁEZ GALLEGO, C. "Global Reporting Initiative, La historia de un éxito". Revista de Responsabilidad Social de la Empresa, n'.3, septiembrediciembre 2009, pp.191-201

BLASCO VÁZQUEZ, J.L. y ELORTZ ARTEGA, I. "Informes de responsabilidad corporativa: la historia de un éxito". Estrategia Financiera, n.257, enero, 2009, pp.26-29.

CAÑIBANO, L. y SANCHEZ, P. "Measurement, Management and Reporting on Intangibles: State of the Art", Readings son Intangibles and Intellectual Capital. Madrid: AECA, 2004.

CAÑIZARES, J. "Entidades responsables", UNE La revista de AENOR, $\mathrm{n}^{\circ} 248$, abril 2010, pp.48-51.

CARRILLO DURÁN, M.V. y NUÑO MORAL, M.V. "La documentación en la evaluación y gestión de la imagen corporativa". El profesional de la información, no 2/Vol. 19., marzo-abril 2010 pp., 123-131.

COMISIÓN DE LAS COMUNIDADES EUROPEAS, Libro Verde. Fomentar un Marco Europeo para la Responsabilidad Social de las Empresas. Bruselas, 18 de julio de 2001, COM (2001) 366 Final. Disponible en www.eur-lex.europa.eu. (Consultada: 26/3/2012).

COMISIÓN DE LAS COMUNIDADES EUROPEAS, Comunicación de la Comisión relativa a la Responsabilidad Social de las Empresas: Una contribución 
empresarial al Desarrollo Sostenible. COM (2002)347. Disponible en www.eurlex.europa.eu (Consultada: 26/3/2012).

COMISIÓN EUROPEA, Comunicación para poner en práctica la asociación para el crecimiento y el empleo: hacer de Europa un polo de excelencia de la Responsabilidad Social de las Empresas", Bruselas, 22 de marzo de 2006, COM (2006) 136 final. Disponible en http://eurlex.europa.eu/LexUriServ/LexUriSErv.do?uri=COM20-06:0136:FIN:ES:PDF (Consultada: 26/3/2012).

COMISIÓN DE LAS COMUNIDADES EUROPEAS, Comunicación de la Comisión al Parlamento Europeo, al Consejo, al Comité Económico y Social Europeo y al Comité de Regiones, "Estrategia renovada de la Unión Europea para 2011-2014 sobre Responsabilidad Social de las Empresas (RSE)", de 25 de octubre de 2011. COM (2011) 681 final. Disponible en www.eur-lex.europa.eu (Consultada: 26/3/2012).

CHARLO, M. y MOYA, I. "El comportamiento financiero de las empresas socialmente responsables". Investigaciones Europeas de Dirección y Economía de la Empresa. Vol. 16-2, 2010, pp. 15-26.

DEL REY GUANTER, S. "Responsabilidad social empresarial y orden social: algunas reflexiones sobre sus conexiones semánticas (o terminológicas) y sustanciales.”, en AA.VV., FERNÁNDEZ AMOR y GALA DURÁN (coords.), La responsabilidad social empresarial: un nuevo reto para el Derecho.. Madrid: Marcial Pons, 2009, pp. 43-44.

DOPAZO FRAGUÍO, P. "El jurista ante la gerencia del riesgo y la responsabilidad social corporativa", en AA.VV., CARRETERO, C. y DE MONTALVO JÄASKELÄINEN, F. (dir.), Retos de la abogacía ante la sociedad global. Madrid: Civitas-Thomson Reuters, 2012, pp. 785-799.

DURÁN HERRERA, J.J. "Gobernanza, responsabilidad social y medioambiental de la empresa multinacional. Proceso estratégico". Revista de Responsabilidad Social de la Empresa, $\mathrm{n}^{\mathrm{o}}$. 3, septiembre-diciembre 2009, pp.15-51.

ELKINGTON, J. Cannibals with Forks: The Triple Bottom Line of 21st Century Business, Capstone, Oxford 1997.

-GJøLBERG, M. "¿Cuantificando lo incuantificables? Creación de un índice de prácticas de RSE y rendimiento d la RSE en 20 países", Revista de Responsabilidad Social de la Empresa, $\mathrm{n}^{\circ} .2$, mayo-agosto 2009, pp.15-49.

FRANZONE, D. "Gobernanza Europea”, Gobernanza para el Desarrollo Sostenible. Cuadernos de Sostenibilidad y Patrimonio Natural / 7. Madrid: Fundación Santander Central Hispano, 2005.

FUENTES GANZO, E. "La responsabilidad social corporativa. Su dimensión normativa: implicaciones para las empresas españolas". Revista de la Facultad de Ciencias Económicas y Empresariales, Universidad de León, $n^{\circ}$ 3, 2006, pp.1-20.

GARCÍA ECHEVARRÍA, S. y DEL VAL NÚÑEZ, M.T. Cultura corporativa y competitividad de la empresa española. Madrid: Díaz de Santos, 1993. 
GLOBAL REPORTING INITIATIVE, GRI (2002), Global Reporting Initiative: Sustainability Reporting Guidelines. Disponible en http://www.globalreporting.org (Consultada: 10/11/11).

HERRERO HERNANDEZ, A. "La gestión de la responsabilidad social. El sistema de gestión ética y socialmente responsable propuesto por la SGE 21", Revista de Responsabilidad Social de la Empresa, no. 2, mayo-agosto 2009, pp.199-207.

KPMG, "KPMG International Survey of Corporate Responsibility Reporting 2011". Noviembre 2011. Disponible en http:/www.kpmg.com/ES/es/ ActualidadyNovedades/ArticulosyPublicaciones/Documents/CR_Report_2011.pdf (Consultada: 3-5-2012).

LIZCANO, J.L. y NIETO, P. La Semántica de la Responsabilidad Social Corporativa, Madrid: Asociación Española de Contabilidad y Administración de Empresas (AECA). Documento AECA n ${ }^{\circ} 3 / 2006$.

LIZCANO ÁLVAREZ, J.L., GARCÍA SÁNCHEZ, I. y FERNÁNDEZ BLANCO, A. Normalización de la Información sobre Responsabilidad Social Corporativa. Madrid: Asociación Española de Contabilidad y Administración de Empresas (AECA). Documento AECA n ${ }^{\circ} 7 / 2010$.

NIETO, M. "Difusión de la responsabilidad social corporativa en la empresa española". Economistas, №.106, 2005, pp.32 y ss.

MONEVA, J.M. "Mecanismos de verificación de la información sobre responsabilidad social corporativa". Papeles de Economía Española, nº.108, 2006, 75 y ss. pp.

MONEVA, J.M. y LLENA, F. "Análisis de la información sobre Responsabilidad Social en las Empresas Industriales que cotizan en Bolsa", Revista Española de Financiación y Contabilidad, nº. 87, vol. XXVI, Abril-Junio, 1996, 361-401 pp. Disponible en http://www.aeca.es/pub/refc/articulos.php?id $=0351$ (Consultada: 23-4-2012).

MONEVA, J.M. "Información corporativa y desarrollo sostenible". Economistas, $\mathrm{n}^{\mathrm{o}} .106,2005$, pp.70-72.

MONEVA, J.M. "El marco de la información social y medioambiental de la empresa: análisis de la Global Reporting Institute". Revista Interdisciplinar de Gestión Ambiental, $\mathrm{n}^{\circ}$. 30, 2001, pp. 1-15.

MONEVA, J.M. "La información sobre responsabilidad social de la empresa en el contexto de la reforma contable", en Responsabilidad Social Corporativa. Aspectos jurídico-económicos. Castellón: Universidad Jaume I, 2004, pp. 181-211.

MONEVA, J.M., LLENA, F. y LAMEDA, I. "Calidad de los informes de sostenibilidad de la empresa española", comunicación en el XIII Congreso de la Asociación Española de Contabilidad y Administración de Empresas (AECA), Oviedo, septiembre 2005.

MONJE BALMASEDA, O. "Ejercicio de la abogacía y nuevas tecnologías", en AA.VV., CARRETERO GONZÁlEZ, C. y DE MONTALVO 
JÄÄSKELÄINEN, F. (Directores), Retos de la Abogacía ante la sociedad global. Navarra: Thomson Reuters. Aranzadi, 2012. pp. 1095-1109.

MORALES GUTIÉRREZ, A.C. "Innovación 'abierta`en el Tercer Sector: El modelo organizativo 2.0". ("'Open' Innovation in the Third Sector 2.0: Organization model"). Revista Española del Tercer Sector, $\mathrm{n}^{\mathrm{o}}$. 13. septiembre-diciembre 2009, pp.17-37.

MORENO, J., Responsabilidad social corporativa y competitividad: Una visión desde la empresa, en AA.VV., VARGAS, L. (coord.), Mitos y realidades de la responsabilidad social corporativa en España. Un enfoque multidisciplinar. Navarra: Thomson-Civitas, 2006, pp. 187-223.

OCDE, Declaración de la OCDE sobre Inversión Internacional y Empresas Multinacionales, Disponible en http://www.oecd.org/dataoecd/21/20/16975360 .pdf. (Consultada: 26/4/2012).

ONU, Global Compact - Pacto Mundial. ONU, 1999. Disponible en http://www.pactomundial.org/ (Consultada: 26/4/2012).

OLCESE, A., RODRÍGUEZ, M.A. y ALFARO, J. Manual de la empresa responsable y sostenible. Madrid: McGraw-Hill, 2008, pp.321-322.

PASTRANA PIÑA, J.M. "Modelo de auditoría legal ('due diligence') en operaciones de adquisición societaria". $R d S, \mathrm{n}^{\circ} .34,2010-1, \mathrm{pp} .295-302$.

OZO FERNÁNDEZ, R. del. "El valor de la responsabilidad social corporativa en un entorno de crisis". Estrategia Financiera: Revista para la Dirección Financiera y Administrativa, $\mathrm{n}^{\circ} .257$, enero 2009, pp.30-33.

REDONDO, H. "Cómo integrar la responsabilidad social en la cultura empresarial". Revista Asturiana de Economía, no.34, 2005, pp 31-41.

ROSENBLOOM, A.H. Due Diligence. La guía perfecta para fusiones y adquisiciones, asociaciones en participaciones, alianzas estratégicas. México, D.F.: Limusa-Noriega Editores, S.A., 2005.

SÁNCHEZ HUETE, M.A. "La acción social y la responsabilidad social. Posibilidades y límites de la intervención normativa financiera", en AA.VV., FERNÁNDEZ AMOR y GALA DURÁN (coords.), La responsabilidad social empresarial: un nuevo reto para el Derecho. Madrid: Marcial Pons, 2009, pp. 89-91.

TORTOSA, E. "Responsabilidad social de la empresa: un nuevo modelo de empresa". Papeles de Economía Española, ño.108. 2006, pp.106 y ss.

VILLAGRA, N. "La RSC, su comunicación y la necesidad de una nueva conciencia", en BAJO. A. y VILLAGRA, N. (eds.), Reflexiones en torno a la responsabilidad social en el ámbito de la globalización. Madrid: Universidad Pontificia Comillas, 2008, pp.127-143.

VILLAGRA, N. "¿Por qué tenemos miedo a comunicar la Responsabilidad Social Corporativa?", en BAJO, A. y VILLAGRA, N. (eds.), Evolución conceptual y práctica de una gestión responsable. Madrid: Universidad Pontificia Comillas, 2007, pp.77-92. 